\title{
Semeadura e curva de absorção de água em sementes com e sem alas de Pajeú
}

\author{
Maria Valnice de Souza Silveira ${ }^{1}$, Sinara Barbosa Sousa ${ }^{1}$, Wellington Marcos Soares da Silva ${ }^{1}$, Raimundo \\ Gleidison Lima Rocha ${ }^{1 *}$, Maria Clarete Cardoso Ribeiro ${ }^{1}$
}

\begin{abstract}
Resumo: Este estudo teve como objetivo avaliar a taxa de emergência de plântulas sob diferentes profundidades de semeadura e analisar a curva de absorção de água, em ambos utilizando-se sementes com e sem alas de Pajeú. Os dois experimentos foram conduzidos no Campus das Auroras da UNILAB, em Redenção-CE e o delineamento estatístico utilizado foi o inteiramente casualizados. No primeiro experimento, na semeadura utilizou-se o esquema fatorial (2x3), constituído de sementes com e sem alas, e três diferentes profundidades de semeadura $(1 \mathrm{~cm}, 3 \mathrm{~cm} \mathrm{e} 5 \mathrm{~cm})$, com 4 repetições de 25 sementes cada tratamento. No segundo experimento, foi realizado a embebição em sementes (no laboratório), constituídos por 5 repetições de 20 sementes com e sem alas, respectivamente, submetidas a período de 30 horas. As variáveis analisadas foram: Peso de mil sementes, curva de embebição. Aos 27 dias após semeadura, logo após a última contagem de emergência foi realizada a coleta das plântulas para a avaliação, comprimento da radícula (CR) e massa seca da plântula (MS). Sementes de Pajeú semeadas com alas nas profundidades de 1 e 3 centímetros é adequada para o incremento da taxa de emergência. A submissão a embebição de sementes com e sem alas em água não acelerou a germinação, no entanto, recomenda-se novas pesquisas com as sementes de Pajeú, obedecendo um período maior de embebição.
\end{abstract}

Palavras-chave: plantas silvestres, vigor, Triplaris gardneriana

\section{Sowing and water absorption curve in seeds with and without Pajeú wings}

\begin{abstract}
This study aimed to evaluate the seedling emergence rate under different sowing depths and to analyze the water absorption curve, in both using seeds with and without Pajeú wings. Both experiments were carried out at UNILAB, Campus das Auroras, in Redenção-CE and the statistical design used was completely randomized. In the first experiment, the sowing scheme was used (2x3), consisting of seeds with and without wings, and three different sowing depths (1 cm, $3 \mathrm{~cm}$ and $5 \mathrm{~cm}$ ), with 4 repetitions of 25 seeds each treatment. In the second experiment, the seeds were soaked (in the laboratory), consisting of 5 repetitions of 20 seeds with and without wings, respectively, submitted to a period of 30 hours. The variables analyzed were: Weight of a thousand seeds, imbibition curve. At 27 days after sowing, just after the last emergency count, seedlings were collected for evaluation, taking the characters: seedling emergence percentage (E\%), height of the aerial part of the seedlings (HAP), radicle length (RL) and seedling dry mass (SM). Pajeú seeds sown with wings at depths of 1 and 3 centimeters is suitable for increasing the emergence rate. Submission to imbibition of seeds with and without wings in water did not accelerate germination, however, further research with Pajeú seeds is recommended, obeying a longer period of imbibition.
\end{abstract}

Keywords: irrigated agriculture in semi-arid, chemical degradation, labile fractions

\section{INTRODUÇÃO}

A Triplaris gardneriana (Wedd.) (Polygonaceae), comumente conhecida como pajeú ou pau formiga é uma planta com características ornamentais, com porte arbustiva, de ampla distribuição no Brasil, com destaque nos estados de Alagoas, Bahia, Ceará, Maranhão, Pernambuco, Piauí, Goiás, Mato Grosso, Minas Gerais e Paraná, segundo dados de The Brazil Flora Group (BFG, 2015). Ocorre naturalmente na região da caatinga, e está entre as espécies indicadas para recuperação de áreas degradadas, utilização em sistemas agroflorestais (SAFs) e recuperação de florestas ciliares (LORENZI, 2002).
Possui também ações etnomedicinais associadas a casca do caule, raízes e folhas, na forma de chá frio, lambedor, cozimentos e banho de assento. Bastante usada na medicina popular, contra câncer, gastrite, úlcera, tosse, dor, azia, gripe e reumatismo, tratamento da blenorragia, leucorréia, hemorróidas sangrentas e inflamação dos órgãos internos. $\mathrm{O}$ extrato das sementes possui ação antibacteriana, antioxidante e anticolinesterásica (PEREIRA JÚNIOR, 2014; FARIAS et al., 2013).

O Pajeú possui sementes aladas, o que facilita a dispersão a longas distâncias e em locais variados, através dos ventos. Entretanto, por ser considerada sementes ortodoxas (quiescentes), pela rápida redução no teor de água no final da maturação, alguns ambientes mostram-se limitantes à germinação pela

Recebido em 11/03/2020; Aceito para publicação em 08/04/2021

${ }^{1}$ Universidade da Integração Internacional da Lusofonia Afro-Brasileira-UNILAB.

*email: rochaagronomia@ hotmail.com 
falta de água disponível na semente (PEREIRA, 2011 e SILVA, 2010).

$\mathrm{O}$ tegumento das sementes exerce papel importante no processo de germinação, pois é um fator regulador do processo de absorção de água (MCDONALD et al., 1988). Ao induzir o processo de embebição a absorção de água em sementes secas estimula todas as atividades metabólicas, facilitando o rompimento e induzindo o crescimento do eixo embrionário (NASSIF et al., 1998; BEWLEY; BLACK, 1994).

A emergência de plântulas é influenciada pela profundidade de semeadura, uma vez que, o plantio em profundidades com visibilidade da semente em superfície pode comprometer a taxa de embebição, e em profundidades maiores a absorção de água acontece de forma satisfatória (ROCHA, et al., 2017). A profundidade de semeadura é específica para cada espécie e, quando adequada, propicia uniformidade

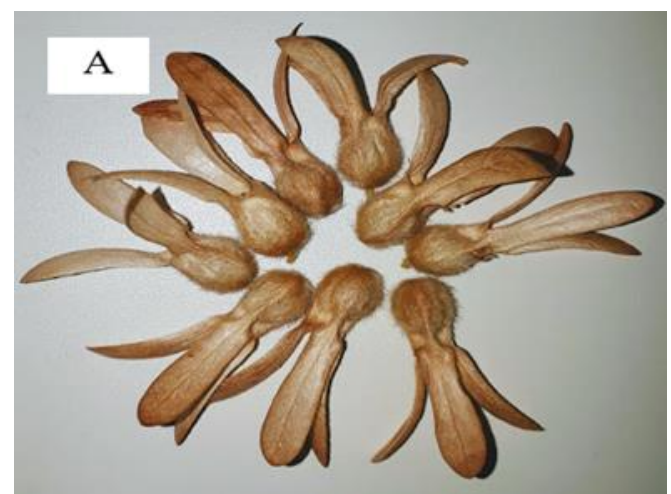

Fonte: própria.

Figura 1. Sementes de Pajeú com alas (A) e sem alas (B).

Para determinação do peso de mil sementes com e sem alas, foi separada toda a porção de mil sementes "Semente Pura", (BRASIL, 2009) calculando-se o peso de mil sementes, mantendo-se o mesmo número de casas decimais utilizando equação 1 abaixo de acordo com a Regra de Análise de Sementes (RAS): $\mathrm{PMS}=\frac{\text { Peso da amostre } x 100}{N \text { o de sementes }} \quad$ (Equação 1) em que: PMS = Peso de mil sementes

Onde, para a obtenção da massa de mil sementes é necessário multiplicar o peso da amostra por cem e dividir o valor obtido pelo número total de sementes.

\section{Experimento 1: Semeadura}

$\mathrm{O}$ experimento foi conduzido na Unidade de Produção de Mudas do Campus das Auroras. A semeadura ocorreu em setembro de 2018 logo após a seleção e beneficiamento das sementes, onde foram cultivadas em recipientes plásticos de $150 \mathrm{~mL}$, perfurados, utilizando-se uma semente por recipiente. Foi utilizado o substrato (areia, esterco bovino e terra) na proporção 1:1:1.

Por ocasião da emergência de plântulas, foi avaliado o índice de velocidade de emergência (IVE) de germinação e emergência de plântulas (SOUSA et al., 2007).

Este estudo teve como objetivo avaliar a taxa de emergência de plântulas sob diferentes profundidades de semeadura e analisar a curva de absorção de água, em ambos utilizando-se sementes com e sem alas de Pajeú.

\section{MATERIAL E MÉTODOS}

O presente estudo foi desenvolvido no Campus das Auroras, da Universidade da Integração Internacional da Lusofonia Afro-brasileira (UNILAB), em Redenção, Ceará. O trabalho foi dividido em dois experimentos, o primeiro referente a semeadura e o outro referente a embebição, ambos os testes foram em sementes com alas (Figura 1A) e sem alas (Figura 1B) de Pajeú. Todos os frutos foram coletados em plantas matrizes de forma aleatória na copa das árvores.

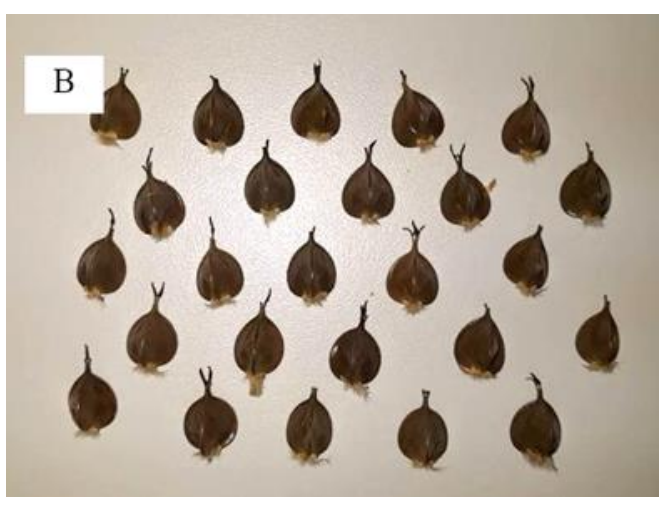

contabilizando o número de plântulas emergidas a cada dia. A coleta de dados perdurou até estabilização da emergência de plântulas (por 16 dias), sendo determinado o IVE de acordo com a fórmula proposta por Maguire, (1962):

$$
\begin{aligned}
& \mathrm{IVE}=\mathrm{E} 1 / \mathrm{N} 1+\mathrm{E} 2 / \mathrm{N} 2+\ldots \mathrm{En} / \mathrm{Nn} \text { (Equação 2) } \\
& \text { em que: }
\end{aligned}
$$

IVE = índice de velocidade de emergência. E1, E2... En $=$ número de plântulas normais computadas na primeira contagem, na segunda contagem e na última contagem. N1, $\mathrm{N} 2 \ldots \mathrm{Nn}=$ número de dias da semeadura à primeira, segunda e última contagem.

Aos 27 dias após semeadura, logo após a última contagem de emergência, foi realizada a coleta das plântulas para a avaliação, tomando-se os caracteres: porcentagem de emergência das plântulas $(\mathrm{E} \%)$, altura da parte aérea das plântulas (APA) aplicando os procedimentos descritos por Nakagawa (1999), comprimento da radícula (CR) e massa seca da plântula (MS) conforme Oliveira et al. (2009). A dimensão da altura de plântulas e comprimento de raiz foi determinada medindo-se com uma régua 
graduada em centímetros. A massa fresca e massa seca da plântula inteira foi determinada em balança de precisão de duas casas decimais.

O percentual de emergência de plântulas obtido após 16 dias de coleta de dados, foi calculado de acordo com Labouriau e Valadares (1976) indicado na equação 3 a seguir:

$E=\left(\frac{N}{A}\right) \times 100$

(Equação 3)

em que: $\mathrm{E}$ - emergência, $\mathrm{N}$ - número total de plântulas emergidas e A - número total de sementes colocadas para emergir.

O delineamento estatístico utilizado foi o inteiramente casualizados (DIC), em esquema fatorial (2x3), constituído de sementes sem alas (Figura 1A) e com alas (Figura 1B), possuindo três diferentes profundidades de semeadura $(1 \mathrm{~cm}, 3 \mathrm{~cm}$ e $5 \mathrm{~cm})$, com 4 repetições de 25 sementes para cada tratamento, totalizando 100 sementes por tratamento.

Os dados foram transformados e em seguida foi utilizado o teste de Scott-Knott a 5\% de probabilidade para normalidade de dados, as médias comparadas pelo teste de Tukey a 5\% de probabilidade, sendo que os dados de porcentagem de emergência foram transformados em $X=\operatorname{arcsen} \sqrt{ }(x / 100)$, utilizando o programa estatístico ASSISTAT 7.7 (SILVA, 2016).

\section{Experimento 2: curva de absorção de água}

Após a coleta e beneficiamento manual das sementes, estas foram separadas por tratamentos onde suas alas foram retiradas, já o outro tratamento predominou-se por sementes constituintes por suas alas intactas, na qual ambos tratamentos foram colocados em imersão em água fria, conforme a metodologia proposta por Piña-Rodrigues, Martins (2012) para sementes que não são dormentes, porém são percebidas em situações em que a germinação é lenta, como foi o caso das sementes deste trabalho, observada no primeiro experimento, justificando assim a necessidade deste outro experimento com teste de embebição.

Para determinar a curva de embebição, as sementes foram colocadas em placa de Petri, em seguida, adicionada água natural da torneira e submetidas a teste de embebição em temperatura ambiente em um período de 30 horas, com o objetivo de facilitar e uniformizar a germinação. As avaliações foram realizadas no Laboratório de Tecnologia de Sementes da UNILAB. O método utilizado foi descrito por Brasil (1992) e usado em sementes que apresentam tegumento duro e que podem germinar mais rapidamente após embebição em água, por um período de 24 a 48 horas.

A cada seis horas as sementes foram colocadas sobre o papel toalha para retirada do excesso de água, logo após, foram submetidas a pesagem em balança de precisão contendo duas casas decimais.

$\mathrm{O}$ delineamento experimental foi inteiramente casualizados com cinco repetições composta por 20 sementes com e sem alas, respectivamente. Foram realizadas quatro pesagens a cada seis horas até atingir as 30 horas de embebição das sementes. Os dados foram submetidos à análise de regressão e os resultados foram representados graficamente utilizando o software Sigmaplot versão 12.5.

\section{RESULTADOS E DISCUSSÃO Experimento 1: Semeadura}

As sementes de $T$. gardneriana possuem emergência lenta. No presente trabalho a emergência ocorreu a partir do $11^{\circ}$ dias após a semeadura, independente do tratamento, estes resultados diferem do encontrado por Reis et al. (2012) em que a emergência de $T$. americana começou no $18^{\circ}$ dia após a semeadura e do encontrado por Sousa et al (2008) em T. surinamensis que ocorreu entre o $7^{\circ}$ e o $9^{\circ}$ dia dependendo do tratamento utilizado. Conforme Oliveira et al. (2009), quanto mais rápido for a velocidade de emergência em condições de campo ou em casa de vegetação, mais vigoroso será o lote de sementes.

Neste trabalho, a emergência foi bem inferior ao esperado (Figura 2), baixos resultados para variável percentual de emergência em sementes $T$. gardneriana também foi verificado em Leite (2017) utilizando plantio direto em áreas de pastagem, na profundidade de 5 centímetros. O baixo índice de emergência pode ser justificado pela dormência fisiológica, por se tratar de sementes das espécies da família Polygonaceae como é relatada em Torres, (2008) quando a semente apresenta embrião periférico. 


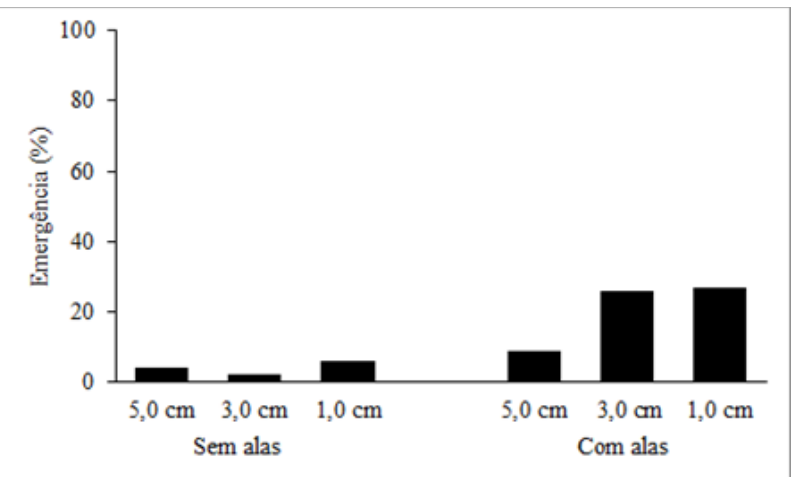

Figura 2. Percentual de emergência de sementes com e sem alas de Pajeú em função das profundidades de semeaduras.

$\mathrm{O}$ peso de mil sementes referente a sementes com alas foi de $182,85 \mathrm{~g}$ e o peso das sementes sem alas foi de $151,86 \mathrm{~g}$, o que corresponde a 5.468 e 6.585 sementes por quilograma, respectivamente. Entretanto, esses dados não se assemelham aos encontrados por Araújo Neto et al., (2018) em T. brasiliana Cham., pois obtiveram em média 20,9 (g) por mil unidades de sementes, equivalente a 47.900 sementes por quilograma. Araújo Neto et al., (2018) destaca que essas variações da massa da semente ocorrem devido a vários fatores ligados ao meio ambiente em que está inserida, fatores estes que podem interferir positivamente ou negativamente durante sua formação, e não aos fatores genéticos da planta.

$\mathrm{Na}$ tabela do quadrado médio observa-se que houve interação significativa para todas as variáveis analisadas. Entretanto, na variável massa seca total da plântula (g) não houve diferença significativa, devido ser mínima a diferença no peso das médias dos tratamentos (Tabela 1).

Tabela 1. Efeito da interação para o Índice de velocidade de emergência (IVE); Altura da parte aérea (APA); Comprimento da radícula (CR); Massa seca total (MS) em sementes com e sem alas de Pajeú em função das profundidades de semeaduras.

\begin{tabular}{lllllc}
\hline & \multicolumn{5}{c}{ Quadrado Médio } \\
\hline Fator de variação & GL & IVE & APA & CR & MS \\
\hline Sem alas x com alas & 1 & $0,50^{*}$ & $7,91^{*}$ & $235,74^{* *}$ & $0,38^{\mathrm{ns}}$ \\
Profundidades & 2 & $0,08^{*}$ & $7,90^{* *}$ & $71,25^{*}$ & $0,41^{\mathrm{ns}}$ \\
Sem alas x com alas x profundidade & 2 & $0,08^{*}$ & $6,20^{*}$ & $93,86^{* *}$ & $0,70^{\mathrm{ns}}$ \\
Tratamentos & 5 & $0,17^{* *}$ & $7,22^{* *}$ & $113,19^{* *}$ & $0,52^{\mathrm{ns}}$ \\
Resíduo & 18 & 0,02 & 55,31 & 12,31 & 0,49 \\
\hline
\end{tabular}

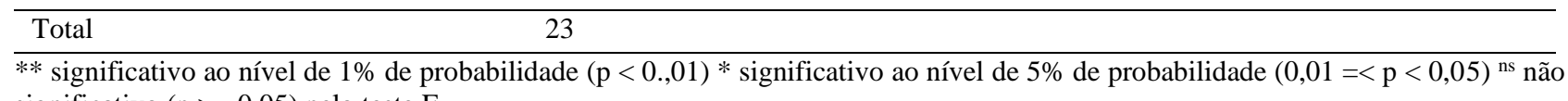
significativo $(\mathrm{p}>=0,05)$ pelo teste $\mathrm{F}$.

Para o índice de velocidade de emergência de plântulas, a profundidade 1 e $3 \mathrm{~cm}$ em sementes com alas foi a que melhor proporcionou um índice de emergência ao longo dos 26 dias de avaliação a partir da semeadura (Tabela 2). Resultados semelhantes foram obtidos por Motta et al. (2006), que verificaram que em sementes de Mutamba (Guazuma ulmifolia Lam.) semeadas em menor profundidade, apresentaram uma maior taxa de emergência de plântulas no campo, do que as semeadas em maior profundidade $(4 \mathrm{~cm})$. Também foi verificado em Perez et al. (1999) ao ter trabalhado com a canafístula
(Peltophorum dubium), assim aborda que a profundidade adequada de semeadura em campo foi de $1 \mathrm{~cm}$.

As sementes sem alas apresentaram os menores valores de emergência em todas as profundidades estudadas, entretanto o IVE na profundidade de $5 \mathrm{~cm}$ não diferiu estatisticamente de sementes com alas nas profundidades de 1 e $3 \mathrm{~cm}$. Contudo, a remoção da ala das sementes de Pajeú não proporciona aumento no percentual de plântulas emergentes. Entretanto, emergência de sementes de T. gardneriana é influenciada pela profundidade de semeadura.

Tabela 2. Dados médios de percentual do índice de velocidade de emergência (IVE) de sementes com e sem alas de Pajeú em função das profundidades de semeaduras.

\begin{tabular}{cccc}
\hline Diferentes formas de semeadura & \multicolumn{3}{c}{ Profundidades $(\mathrm{cm})$} \\
\cline { 2 - 4 } & $5(\mathrm{~cm})$ & $3(\mathrm{~cm})$ & $1(\mathrm{~cm})$ \\
\hline Sem alas & $0,09 \mathrm{aA}$ & $0,05 \mathrm{bA}$ & $0,13 \mathrm{bA}$ \\
Com alas & $0,15 \mathrm{aB}$ & $0.49 \mathrm{aA}$ & $0,50 \mathrm{aA}$ \\
\hline CV $\%$ & 61,77 & &
\end{tabular}

As médias seguidas pela mesma letra não diferem estatisticamente entre si. Foi aplicado o Teste de Tukey ao nível de 5\% de probabilidade pelo teste $\mathrm{F}$. 
Na variável altura da parte aérea, menores valores foram encontrados quando utilizado o tratamento de sementes sem alas na profundidade de três centímetros. Nos demais tratamentos não foram obtidos diferenças significativas entre si (Tabela 3 ).

Tabela 3. Dados médios da altura da parte aérea, em centímetros, de sementes com e sem alas de Pajeú em função das profundidades de semeaduras.

\begin{tabular}{cccc}
\hline Diferentes formas de semeadura & \multicolumn{3}{c}{ Profundidades } \\
\cline { 2 - 4 } & $5(\mathrm{~cm})$ & $3(\mathrm{~cm})$ & $1(\mathrm{~cm})$ \\
Sem alas & $4,32 \mathrm{aA}$ & $1,08 \mathrm{bB}$ & $4,32 \mathrm{aA}$ \\
Com alas & $4,33 \mathrm{aA}$ & $4,26 \mathrm{aA}$ & $4,58 \mathrm{aA}$ \\
\hline CV $\%$ & 27,08 &
\end{tabular}

As médias seguidas pela mesma letra não diferem estatisticamente entre si. Foi aplicado o Teste de Tukey ao nível de 5\% de probabilidade pelo teste $\mathrm{F}$.

Na variável comprimento de radícula, menores resultados foram encontrados no tratamento sem alas, na profundidade de três centímetros. Os demais resultados não tiveram diferença estatística entre si (Tabela 4).

Tabela 4. Dados médios do comprimento de radícula em centímetros de sementes com e sem alas de Pajeú em função das profundidades de semeaduras.

\begin{tabular}{cccc}
\hline Diferentes formas de semeadura & \multicolumn{3}{c}{ Profundidades } \\
\cline { 2 - 4 } & $5(\mathrm{~cm})$ & $3(\mathrm{~cm})$ & $1(\mathrm{~cm})$ \\
Sem alas & $12,00 \mathrm{aA}$ & $3,00 \mathrm{bB}$ & $15,11 \mathrm{aA}$ \\
Com alas & $14,80 \mathrm{aA}$ & $17,16 \mathrm{aA}$ & $16,99 \mathrm{aA}$ \\
\hline CV \% & 26,64 & \\
\hline
\end{tabular}

As médias seguidas pela mesma letra não diferem estatisticamente entre si. Foi aplicado o Teste de Tukey ao nível de $5 \%$ de probabilidade.

Os resultados mostram que a massa seca total das plântulas não demonstrou diferença significativa estatisticamente entre si, quando aplicado o Teste de Tukey a 5\% de probabilidade (Tabela 5). Segundo Neto et al. (2018), ao se trabalhar com caracterização morfométrica, germinação e conservação de sementes de Triplaris brasiliana Cham. (polygonaceae), encontraram resultados semelhantes na massa seca de plântulas, não havendo diferença significativa entre as médias dos tratamentos.

Tabela 5. Dados médios da massa seca total de plântulas (g) de sementes com e sem alas de Pajeú em função das profundidades de semeaduras.

\begin{tabular}{cccc}
\hline Diferentes formas de semeadura & \multicolumn{3}{c}{ Profundidades $(\mathrm{cm})$} \\
\cline { 2 - 4 } & $5(\mathrm{~cm})$ & $3(\mathrm{~cm})$ & $1(\mathrm{~cm})$ \\
\hline Sem alas & $1,45 \mathrm{Aa}$ & $0,43 \mathrm{aA}$ & $1,11 \mathrm{aA}$ \\
Com alas & $1.13 \mathrm{aA}$ & $1.30 \mathrm{aA}$ & $1.32 \mathrm{aA}$ \\
\hline CV \% & 62,63 & & \\
\hline
\end{tabular}

As médias seguidas pela mesma letra não diferem estatisticamente entre si. Foi aplicado o Teste de Tukey ao nível de 5\% de probabilidade.

\section{Experimento 2: curva de absorção de água}

Verificou-se que as sementes com alas submetidos a curva de embebição obtiveram um ponto de máximo ganho de peso às 21 horas. Entretanto, sementes sem alas demonstraram um comportamento linear crescente ao longo das épocas de avaliação, porém, demonstraram menores valores de ganhos de peso em relação às sementes com alas. Os valores em gramas (g) continuam oscilando dentro do período de 30 horas, tendo em vista que este período ainda não foi suficiente para estabilização total de absorção de água (Figura 3). 


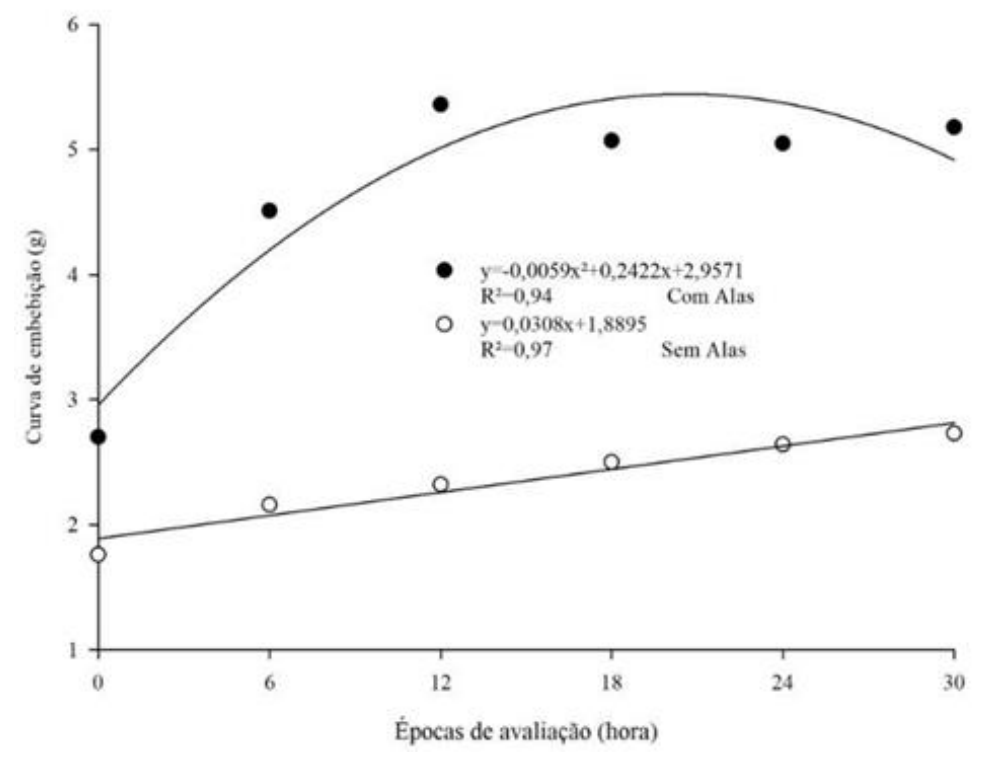

Figura 3. Relação de médias do peso em (gramas) inicial e final observadas na curva de embebição de sementes daT. gardneriana com e sem alas em função ao tempo (hora).

Os resultados não foram satisfatórios, pois não houve emissão de radícula nesse período. Após o teste de embebição, ao adicionar mais sete dias para a verificação da emissão da radícula, foi verificado algumas sementes não foram atacadas por microrganismos, concluindo-se que era somente vivas e ainda apresentavam atividade metabólica, mesmo não havendo surgimento da radícula, e as sementes mortas foram atacadas por microrganismos e apodreceram, como retrata Ferraz, Calvi (2010).

A partir dos resultados deste trabalho, observou-se que o Pajeú mesmo sendo de uma família que não possui dormência, as sementes demonstram comportamentos e resultados não satisfatórios nos dois ambientes testados: campo e laboratório. Apesar das sementes não apresentar tegumento impermeável, não foram capazes de germinar mesmo submetidas a teste de embebição por um período de 30 horas imersas em água.

\section{CONCLUSÕES}

Sementes semeadas com alas nas profundidades de 3 e $1 \mathrm{~cm}$ demonstraram-se ser eficaz para uma maior taxa de emergência de plântulas. A submissão das sementes de Pajeú a embebição em água não acelerou a germinação. Assim, é recomendável novas pesquisas com as sementes de Pajeú, obedecendo-se um período maior de embebição.

\section{AGRADECIMENTOS}

A Universidade da Integração Internacional da Lusofonia Afro-Brasileira (UNILAB). Aos representantes da Unidade de produção de Mudas da UNILAB e a professora Dra ${ }^{a}$. Clarete Cardoso Ribeiro.

\section{REFERENCIAS}

ARAÚJO NETO, J.C.; TEIXEIRA, J.D.; NEVES, M.I.R.S.; MELO, L.D.F.A.; FERREIRA, V.M. Caracterização morfométrica, germinação e conservação de sementes de Triplaris brasiliana cham. (polygonaceae). Ciência Florestal, v. 28, n. 3, p. 949-959, 2018.

BEWLEY, J.D.; BLACK, M. Seeds: physiology of development and germination. New York: Plenum Press, 1994. $445 \mathrm{p}$.

BFG. 2015. Growing knowledge: an overview of Seed Plant diversity in Brazil. Rodriguésia 66: 1085-1113, 2015.

BRASIL, Ministério da Agricultura e Reforma Agrária. Peso de mil sementes. In: Regras para análise de sementes. Brasília: SNDA/DNDV/CLAV, 2009. cap.12, p.345-347.2009.

BRASIL. Ministério da Agricultura e Reforma Agrária. Regras para análise de sementes. Brasília: SNDA/DNDV/CLAV .365p, 1992.

FARIAS, D. F. et al. Antibacterial, antioxidant, and anticholinesterase activities of plant seed extracts from Brazilian semiarid region. BioMed Research International, v. 2013, 2013.

FERRAZ, I.D.K.; CALVI, G.P. Teste de germinação. In: LIMA JUNIOR, M. J. V. (ed.) Manual de procedimentos para análise de sementes florestais. UFAM - ManausAmazonas, Brasil. cap 5 p. 55-122. 2010.

LABOURIAU, L.G.; VALADARES M.E.B. On the germination of seeds of Calotropis procera (Ait) Ait. f. Anais da Academia Brasileira de Ciências, v.48, n.2, p.236-284. 1976. 
LEITE, Jussara Barbosa. Semeadura direta de 36 espécies nativas em área de pastagem abandonada no Distrito Federal. 2017.

LORENZI, H. Árvores brasileiras: manual de identificação e cultivo de plantas arbóreas nativas do Brasil. São Paulo: Nova Odessa, 2002. 386 p.

MAGUIRE, J. D. Speed of germination aid in selection and evaluation for seedling emergence and vigor. Crop Science, Madison, v. 2, n. 2, p. 176-177, 1962.

McDONALD, M.B.Jr.; VERTUCCI, C.W.; ROOS, E.C.Soybean seed imbibition: water absorption by seed parts. Crop Science, v.28, p.993-997, 1988.

MOTTA, M.S.; DAVIDE, A.C.; FERREIRA, R.A. Longevidade de sementes de mutamba (Guazuma ulmifolia Lam. - Sterculiaceae) no solo em condições naturais. Revista brasileira de sementes. vol.28, n.2, Pelotas 2006.

NETO, J.C.A.; TEIXEIRA, J.D.; NEVES, M.I.R.S.; MELO, L.D.F.A.; FERREIRA, V.M. Caracterização morfométrica, germinação e conservação de sementes de Triplaris brasiliana Cham. (polygonaceae). Ciência Florestal, Santa Maria, v. 28, n. 3, p. 949-959, jul.- set., 2018.

NAKAGAWA, J. Testes de vigor baseados na avaliação de plântulas. In: KRZYZANOWSKI, F.C.; VIEIRA, R.D.; FRANÇA-NETO, J.B. (Ed.). Vigor de sementes: conceitos e testes. Londrina: ABRATES, 1999. p.2:1$2: 21$.

NASSIF, S.M.L.; VIEIRA, I.G.; FERNADES, G.D. (LARGEA/). Fatores Externos (ambientais) que Influenciam na Germinação de Sementes. Piracicaba: IPEF/LCF/ESALQ/USP, Informativo Sementes IPEF, Abr-1998.

OLIVEIRA, A..C.S.; MARTINS, C.N.; SILVA, R.F.; VIEIRA, H.D. Testes de vigor em sementes baseados no desempenho de plântulas. Inter Science Place, v. 1, n. 4, 2009.

PEREIRA, M.S. Manual técnico conhecendo e produzindo sementes e mudas da caatinga Fortaleza: Associação Caatinga, 201160 p. Disponível em:< https://www.acaatinga.org.br/wp-

content/uploads/ManualT\%C3\%A9cnicoProdu\%C3\%A7

$\% \mathrm{C} 3 \%$ A3odeSementeseMudas.pdf> Acesso em: $11 \mathrm{de}$ fev. de 2020.

JÚNIOR, L.R.P.; ANDRADE, A.P.; ARAÚJO, K.D.; BARBOSA, A.S. BARBOSA, F.M. Espécies da caatinga como alternativa para o desenvolvimento de novos fitofármacos. Floresta e Ambiente, v. 21, n. 4, p. 509-520, 2014.
PIÑA-RODRIGUES, F.C.M.; MARTINS, R.B. Dormência: conceito, tipos e formas de superação. In: MARTINS, R. B. (Org.). Sementes florestais: guia para germinação de 100 espécies nativas. 1 ed. São Paulo: Instituto Refloresta, 2012. p. 19-26.

REIS, P.S.; ABREU, A.C.G.; MORAIS, R.D.; BALIEIRO, D.C.; FERNANDES, S.S.L.; PEREIRA, Z.V. Efeito de diferentes substratos na germinação das sementes de Triplaris americana L. (Poligonaceae). Cadernos de Agroecologia - ISSN 2236-7934 - Vol 7, n. 2, Dez 2012.

ROCHA, R.G.L.; RIBEIRO, M.C.C.; SILVA, F.D.B. Desenvolvimento inicial do feijão guandu em diferentes profundidades e posições da semente na vagem. Agropecuária Científica no Semiárido, v.13, n.4, p.297301, 2017.

SILVA, F.A.S.E.; AZEVEDO, C.A.V. The Assistat Software Version 7.7 and its use in the analysis of experimental data. Afr. J. Agric. Res, v.11, n.39, p.37333740, 2016.

SILVA, S.G. Disseminação de sementes. Universidade Federal de Uberlândia. Portal do professor, 2010. Disponível em: <http://portaldoprofessor.mec.gov.br/fichaTecnicaAula.ht ml?aula=24831>. Acesso em: 11 de fev. de 2020 .

PEREZ, S.C.J.G.A.; FANTI, S.C.; CASALI, C.A. Influência do armazenamento, substrato, envelhecimento precoce e profundidade de semeadura na germinação de canafístula. Bragantia, Campinas, 58(1):57-68, 1999. Disponível em: <http://www.scielo.br/scielo.php?script=sci_arttext\&pid= S0006-87051999000100008>. Acesso em: 27 de fev. de 2020.

SOUSA, Albanise Ferreira et al. CONTRIBUIÇÃO AO ESTUDO DE Triplaris surinamensis Cham.(TACHI PRETO DA Ví RZEA): FENOLOGIA, BIOMETRIA E GERMINAÇÃO DE SEMENTES. Revista de Ciências Agrárias Amazonian Journal of Agricultural and Environmental Sciences, v. 49, n. 1, p. 9-20, 2008.

SOUSA, A.H.; RIBEIRO, M.C.C.; MENDES, V.H.C.; MARACAJÁ, P. B.; COSTA, D. M. Profundidades e posições de semeadura na emergência e no desenvolvimento de plântulas de moringa. Revista Caatinga, Mossoró, v. 20, n. 4, p. 56-60, 2007.

TORRES, I.C. Presença e tipos de dormência em sementes de espécies arbóreas da Floresta Ombrófila Densa. 2008. 65 f. Dissertação (Pós-graduação em Biologia Vegetal) - Universidade Federal de Santa Catarina. 